$\mathrm{Oz}$

Volume 3

Article 3

$1-1-1981$

\title{
The Future of Architecture: Another Episode in Cultural History or the Return of the Object?
}

David Howard Bell

Follow this and additional works at: https://newprairiepress.org/oz

(c) $($ ) $\Theta \Theta$

This work is licensed under a Creative Commons Attribution-Noncommercial-No Derivative Works 4.0 License.

\section{Recommended Citation}

Bell, David Howard (1981) "The Future of Architecture: Another Episode in Cultural History or the Return of the Object?," Oz: Vol. 3. https://doi.org/10.4148/2378-5853.1018

This Article is brought to you for free and open access by New Prairie Press. It has been accepted for inclusion in Oz by an authorized administrator of New Prairie Press. For more information, please contact cads@k-state.edu. 


\title{
The Future of Architecture:
}

\author{
Another Episode in Cultural History or the Return of the Object? \\ David Howard Bell
}

I detect a crisis of thought, which is manifested by a crisis of language; words no longer meaning anything. - Eugene Ionesco

At some ephemeral shining moment on its path to ruin a collapsing building reveals a maximum of truths about itself. Many of these are simply invisible when the building exists as a static whole. Similarily an historical/cultural epoch reveals the nature of the values and beliefs which bind it together during its dissolution rather than through the facades it erects at the height of its power to explain and identify itself. These facades are dissembling rationalizations which only add to the weight of the epoch's edifice and perhaps under their weight this edifice falls.

It might also be said that these epochs are like spheres in that they appear logically to be constituted of three interlocking parts: 1) an encompassing surface which is the epoch's world-view, 2) a multitude of circles - each is an individual self and 3) a Deity figure which radiates from an exclusive center and organizes the multiplicity of selves and the world-view into a coherent whole. In any cultural continuum these three inevitably become bound up with one another in a relationship which appears deceptively "natural." Invariably the truth of any events that occur in such a period becomes obscured ${ }^{1}$ But when the quasi-natural relationship between these three begins to weaken, fissures erupt on the surface of the sphere. And like sculptor Arnaldo Pomodoro's SFERA No. 6 (fig. 1) an interior of events is revealed that has no obvious relationship to the unifying order and geometrical certainty promised by the sphere's surface.

Just such a situation occurred in architecture in the mid- and lateeighteenth and early-nineteenth centuries as the cultural glue which incontrovertibly bound signifiers and signifieds disintegrated. G.B. Piranesi published in 1743 a collection of drawings entitled Prima Parte di Architettura e Prospettive which depicted buildings and urban spaces of fantastic and sublime configurations (fig. 2). These abrogated the "natural" meaning of the architectural components and rules of the past. A similar attitude was visible in France in the visionary, almost absurd, work of E.L. Boullee (fig. 3) and J.J. Lequeu (fig. 4). These and other architects began to improvise new rules of architectural composition because they realized that the absolutism of classical culture was declining and that, therefore, its forms were not endowed with intrinsic meaning. They were reacting also to the erosion of the rules brough on by rococo decorative excesses and the lack of opportunities to build on a level commensurate with their ideas. These architects imbued with new meaning the cast-off elements and formal geometries of the exhausted classical order and demonstrated the possibility of an entirely arbitrary relationship between form and meaning. They saw

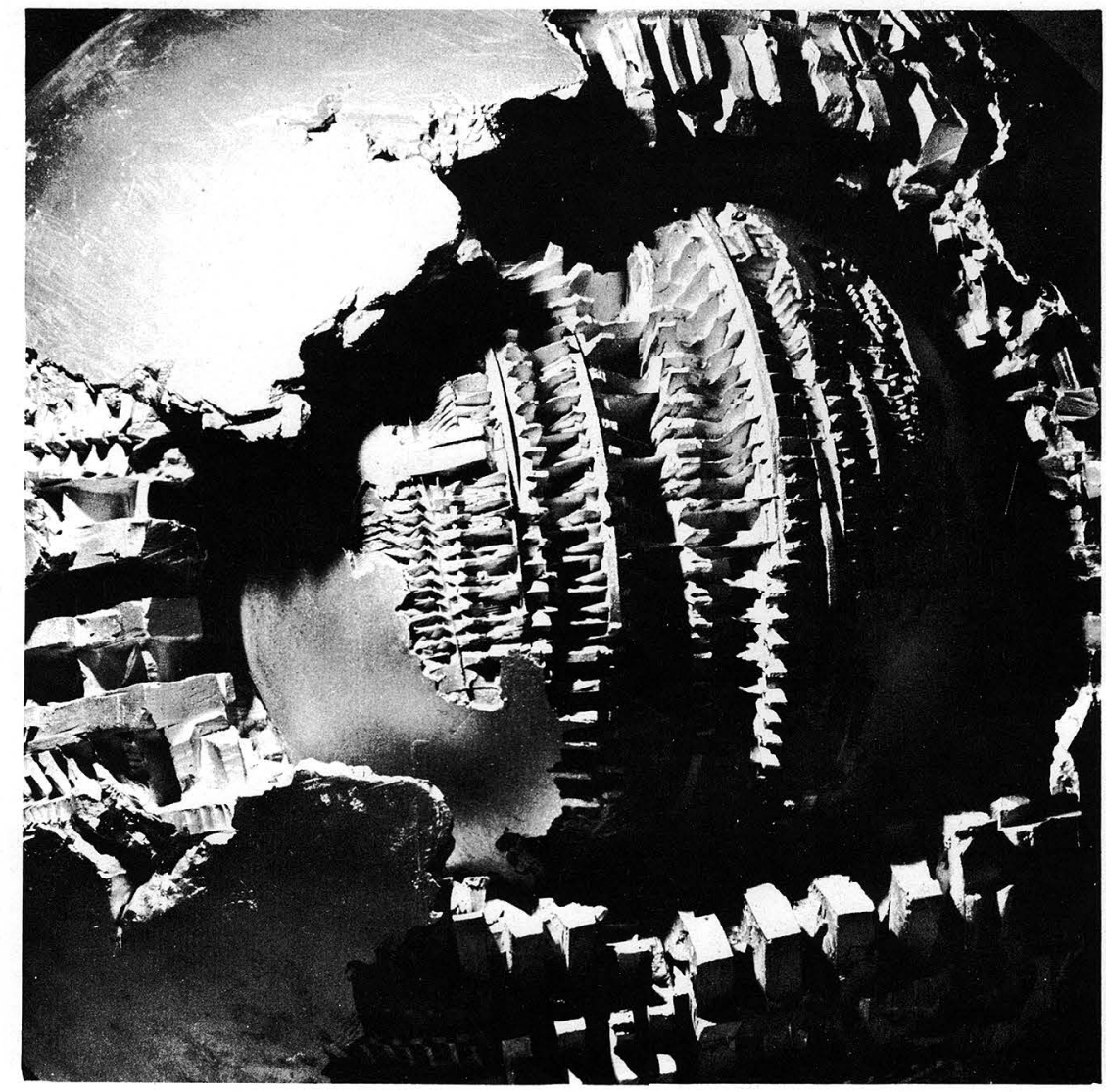

form as not being bound by divine or natural law to a particular meaning and thus could believe that architecture was not a necessary expression of a cosmological condition or world-view. This new awareness was expressed architecturally by the gargantuan scale or bizarre conflation of any or all of the parts of the building; or by a startling combination or juxtaposition of the building with nature as if to suggest the independence of one from the other as objects (fig. 5). But along side this revolutionary fervor was a growing awareness of and uncertainty about the future. With an increasing consciousness of his own scientific method of explaining events Western man schematized that past as narrative cultural history. Under the aegis of the Zeitgeist, the machine to a rational future, a new natural paradigm emerged. Signifiers were quickly reglued to signifieds in a way appropriate to the new times. At that past and an increasing faith in the 

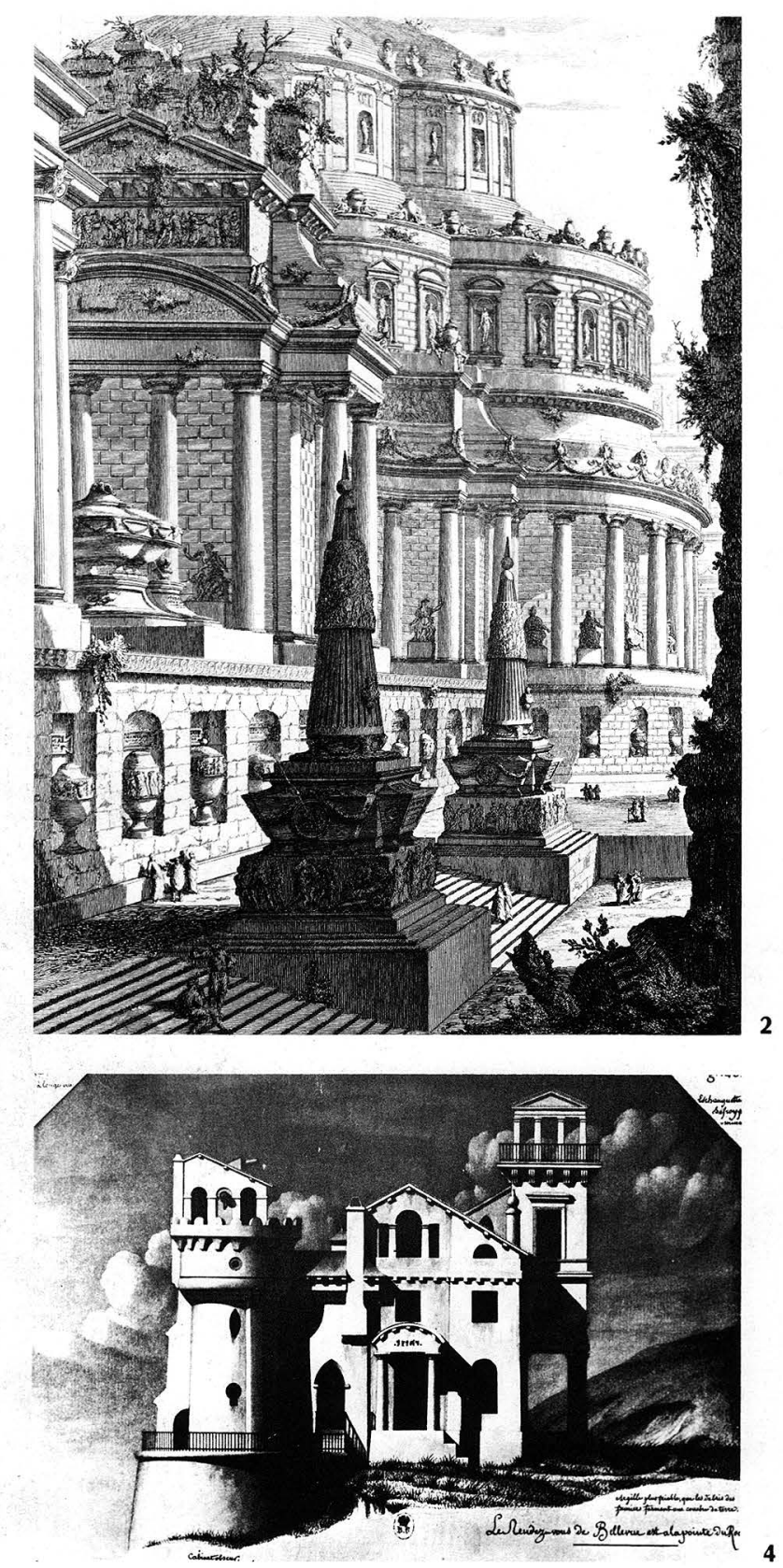

point not only was there an emphatic belief that there are specific architectural forms that have an inherently natural priority and meaning, but that such a linkage was an historical necessity and inevitability. Thus the avant garde emerged to show man his inevitable future as an extrapolation of the present.

This complex of notions has extended into the twentieth century up to our own time. But now, as in the eighteenth century, the paradigm seems to be collapsing. As it collapses the nakedness of events; i.e., the essential anomalousness of architectural forms, long concealed by the prolix explanations of cultural history becomes evident. Again questions and bewilderment have begun to appear in architectural works as diverse as those of Louis Kahn, Peter Eisenman, Aldo Rossi, The Krier brothers, the New Wave Japanese and others. Again and presumptuously a system of explanation (Post-Modernism) as yet incip-
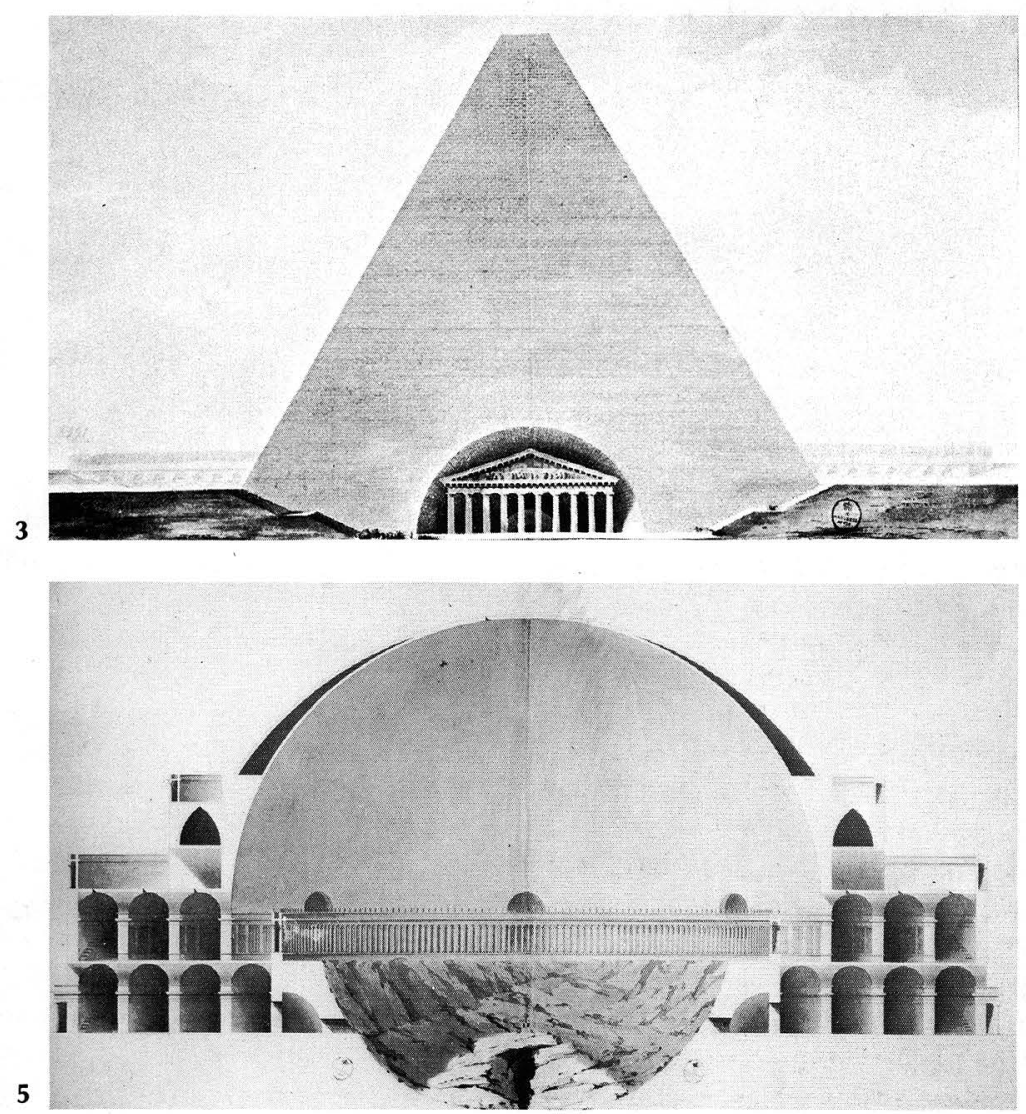
1. SFERA No. 6, Arnaldo Pomodorn 4. Rendezvous,
Bellevue, France,
2. Ancient Mausoleum, G.B. Piranesi
3. Project for a Pyramid Uffizi, Florence E.L. Boulle
5. Project for a Temple to Nature, Uffizi, Florence E.L. Boullee

ient, much disputed and perhap self-abortive is arising to cast a cloak of comfortability and respectability over this nakedness. What is it that seduces us to live continually within periods of cultural deception; is it human necessity or can this circle be broken?

Earlier in my career a colleague and I spent a great deal of time and much argument attempting to develop a system by which we could categorize all architectural activity. One day he presented a list of four broad, inclusive categories. 2 Through the ensuing debate we resolved to our satisfaction the definitions and purposes of these categories. In addi- tion to specifying the grounds for architectural activity these categories had to be inclusive and general almost to the point of their dissolution. They had to allow for various levels of sub-categories and their application had to be responsible for the creation of architecture. Even though these categories themselves are non-hierarchical their application could yield something hierarchical. Eventually we came to believe that not only did these four categories define the creation of an architectural object, but any kind of object. These four principal categories also may be inter-active so that qualities of one may appear in the others 
These four are: ${ }^{3}$

STRUCTURE: The order or patterns of organization which human activity consciously and/or unconsciously imposes on the world around. This can also be called form. STRUCTURE is an intellectualized abstraction, a diagram which mediates the ideal with the material worlds.

CONTENT: The concrete manifestation of events occurring within the abstract framework called STRUCTURE. CONTENT is one of the sets of value-free things which STRUCTURE organizes. It simply is the various components of architecture.

INTENTION: An array of values and concepts imposed by human beings as mind, will and experience on the environment, singly or collectively, in the conscious performance of any activity. When one speaks of INTENTION in architecture one is speaking of what architecture is about, its meaning

OPERATION: The realization of INTENTIONS to the level of STRUCTURE and CONTENT that includes all the devices; i.e., techniques available to the architect, for shaping INTENTIONS, STRUCTURE and CONTENT.

This system is simply applied and requires no special methodological rigor. To begin one simply jumps in at any point of the loop created by the four categories and their subcategories and uses these both as a mnemonic and as a table of critical comparison. The aim of this system for us was the identification and elaboration of architectural and architectonic types based on historical precedent and the development of new such types by the architect.

Although this system seemed complete yet open-ended I suspected that somehow we were deluding ourselves. I had at that time a notion that significant architectural principles always came in clusters of five $^{4}$ and was very perplexed be- composed of four categories. It was also at this time that I was reading Martin Heidegger's "The Question Concerning Technology." 5 In this essay Heidegger re-states Aristotle's four causes which are involved in the creation of any object - causa materialis, causa formalis, causa finalis and causa efficiens. ${ }^{6}$ Heidegger's description of these was remarkably similar to our categories of CONTENT, STRUCTURE, INTENTION and OPERATION respectively. He states that when instrumentality is traced back to this fourfold causality technology in the broadest sense discloses itself as a means. His elaboration of this idea and its implications showed me that my hunch was correct about a missing entity in our system. However, this entity is not really a category, but a field within which these causes are located.

When we developed our four categories we premised them tacitly on a particular worldview, a pluralistic one in the tradition of Jefferson's $E$ pluribus unum or Berlage's Einheid in Vielheid. It was a world-view unsympathetic to bureaucratization, institutionalization and centralization and, although sensitive to new and different artistic ideals, was not object-oriented as we believed, but rather product-oriented. Our system also implied as important the need to make visible the process by which the architectural object is produced. But there were several bothersome things about this. Our institutionalization of the process was based more generally on our good intentions of making the environment more visible and comprehensible. But this act can lead to the environment's becoming a product. Likewise it harbors the phantom of interpretation. Any object qualities that this product has are consumed by revealing the process of its making. And its "materiality" is destined to become consumed by those whose immediate needs it meets. All the effort of design results only in translation. Where was the art? Our system proposed a means for creating architecture, but only as a formally clever instrumentality not as a poetic bringing forth. The categories that we established, together with their application, were indeed a challenge to architecture to reveal itself. But they constituted a command from the mind that demanded the eyes to see a certain way and the things seen to appear in a certain way.

It must be clear: our interests were, and still are, in objects not objectification. The object qualities we sought in our work must not be confused at all with the Victorian objectivity of some behaviorists who naively believe that the architect can stand back from events, view them with "scientific" objectivity and, by applying a utopian, mathematical strategy, always get the "right" answer to every "problem." We believed instead that the world will not kindly stand still while man measures it, that things are ephemeral and that just by our very presence and intervention the design situation is altered.

Our system for designing and/or criticizing architecture was developed in opposition to the tyranny of single, exclusive, apodictic meanings and the belief in sacrosanct interpretations. We believed instead that any interpretation of architectural form has a potential validity to be derived by the individual within a particular context. This allowed us as architects to assign meanings to concatenated architectural form which we felt it should contain as well as allowing the user of the built form to extract his own meaning as well as ours. It must be re-iterated that it was important to us that our work should never resist ultimate interpretation on some level. We, in fact, believed this to be not only necessary but inevitable. Our prime requirement was that all things must somehow be explainable; i.e., brought to human consciousness through our very loose, all-encompassing system. This put us into the business of suggesting various ways to concoct doubles for architecture - the more of these the better. The fact is that such an interpretive constellation is a manifestation of some dissatisfaction with the object and represents a desire to replace it with something else. "To interpret is to impoverish, to deplete the world - in order to set up a shadow world of 'meanings.' It is to turn the world into this world. ('This world'! As if there were any other)." Therein lay the hubris of technical man as the conscious orderer of nature. Our biases in favor of interpretation merely obscured the Being of architecture - the object of desire. In addition to our unconscious assumption of the infinite expandability and inclusiveness of our four categories we placed a premium on our conscious abilities as designers. We made no allowance for the appearance of the anomalous - if it appeared it could or should be explained by our system and absorbed. The anomaly, whatever it might be, would never be allowed to reveal itself simply as it is

This need to suppress or explain the anomalous is what Heidegger calls the danger inherent to Enframing. Enframing he defines as a challenging claim made by Nature to man to challenge forth, i.e., to order as a "standing-reserve" that which reveals itself to man via his application of the four casual categories. Gregory Bateson terms this phenomenon the paradox of conscious purpose: In order to survive mankind must act purposefully yet to do so leads to the disruption of the systems which we depend upon for survival. Furthermore, purposefulness is intrinsic to consciousness, its use cannot be foresworn. ${ }^{8}$ The Cartesian epistemotogy, which underlays much modern thought, allows man to have a certainty about the nature and existence of things through his consciousness. It permits man to represent reality to himself and treat this representation as an object of thought. This reality is a model of conscious thought and hence controllable through the methods of conscious thought; i.e., rationalism This reality, however, is an illusory idee fixe because it does not focus 
on something beyond man, but rather on something in his consciousness. Modern technology like handicraft, poetry, painting and ancient shipbuilding is a revealing, but unlike them it is a challenge put forth to nature to supply energy that can be extracted and stored. Modern technology further is not simply the development and manufacturing of labor-saving devices and the instruments of research, but is also management, administration, $\mathrm{fi}$ nance and even the arts when they are in the service of cultural history. It has as its aim the complete reordering of Nature in accordance with the humanistic model of consciousness. It is the construction of a double for Nature in man's image a utopia. This double is opposed to the heterogeneity and tendency toward diversification that characterizes Nature: it moves instead toward centralization, homogeneity and total coherence among its constituent parts. Tine danger that lies in Enframing, which will not allow anomalies to appear, is a challenging, followed by an unlocking or extraction, then a transformation of what is unlocked. This transformed matter is then stored-up as a "standing-reserve" and ultimately distributed as a product that is transferred and translated about. Because this occurs within the province of the four casual categories it is a revealing, but it is one that never leads to an object. That which is revealed by challenging forth and ordered to stand by in readiness for use always lies within a cycle of means and ends, therefore its essence becomes open to and possibly lost within the realm of multiple interpretation.

When it is caught up in the horrifying movement to homogeneity dictated by the web of means and ends the essence of an object cannot endure as that which is revealed. Objects surrender their permanence to become orderable and substitutable. The production, distribution and consumption of petroleum and the critical dependence that every aspect of survival has on such activities brings to immediacy the abstractness of this notion of Enframing. Questions of quality within this great web of order have no importance unless they can be seen in terms of being beneficial to its ends

Western man has consistently thought of objects primally as self evident because of their apparent readiness for use or at-handness Suppose, however, we think abou objects not as self-evident, but instead as those things which only reveal themselves ultimately? Architects profess concern for objects and with too much frequency harbor guilt about this concern. There is small cause for wonder in this since object orientation has been vitriolically criticized in so many ways as being hedonistic, irresponsible and irrelevant. But the critics have simply forgotten or wanted to forge that objects exist. The object of such criticism is nothing but a phantom of the real object, which has been obscured by man's desire to se everything in the world up in a continuous linkage as a standing reserve in readiness for use. Thu instead of a concern for objects modern man has become infatuated with mastering techniques valuable to the means and ends cycle. Whether these techniques masquerade as aesthetic/cultural proficiencies or pseudo-scientific ones, in architecture as with other human activities each is an illusory de parture from the whole, a mere interpretation of the whole. Thi whole for which man has frantically searched is itself never capable of being ordered by conscious action because consciousness itself is only part of the mysterious body of man.

When that which is revealed no longer concerns man as an object outself himself, i.e., as an anomalous presence, but rather is seen as something in readiness for use within a perfect web of relationships with similarly denatured objects man himself ultimately will come to be seen in such terms as a standing reserve. Man assumes that this position from which he has everything in nature ready at hand for his use makes him the master of the earth. This, it must be re-iterated, is the great danger of Enframing. Having consumed nature, and this is only man's version of nature not Nature itself, Nature will not as an animated entity gain retribution. Nor will Nature withdraw from man. These are silly romanticized anthropocentrisms. Nature will simply be excluded. Having consumed his version of nature man will draw his web of technique into an evertightening circle around himself. Excluding the world of objects and everything which has no use to him man will find himself in complete suspension in space and commit the ultimate cannibalism by consuming the only thing left - himself

The saving power, as Heidegger calls it is not a deliverance or redemption. It lies within the danger of Enframing, beside it. Enframing is not exclusively within man nor is it another definition of man's will-topower; it only appears this way. Enframing is a challenge issued by Nature to man to challenge it Nature is, in this case, what is outside of man, but in which he stands. The saving power is man's latent ability to open up to this simple realization, a realization which is the "essence of Technology." This essence is not wheels or gears or columns or beams or bureaucratic structure or management technique. It is the realm in which it has been given to us to carry out our lives. In reference to the system that my colleague and I developed this was called CONTEXT; Heidegger calls it Being. This Being is a kind of communication of the object to us of its unique existence outside our efforts to capture it within the efficient snares of our conscious intellectuality. As we become aware of the Being that Enframing attempts to reveal we will tend more not "to think," not to strive "to know," not "to plan," not "to order." We will tend not to set the world up for use, nor challenge things to appear as we desire them to be in the arrogant sameness of our own image, but to reveal themselves to us as they are in the goodness of their difference from us. This was the genius of Louis Kahn's architecture and for us it is what lies beyond the final jury just as it patiently awaited the first one.

ACD

\section{NOTES}

1. Michel Foucault, "Theatrum Philosophicum," Language, Counter-Memory Practice, Cornell University Press, 1977.

2. I am indebted to Tom Clark, a former colleague of mine at both Kansas State University and The Design Studio in Manhattan (Kansas, of course), for these insights and the many pleasurable hours we had railing at another about their meaning and significance. Tom is now a project architect with RTKL in Baltimore Maryland

3. Similar rationalizations of architect ural production had been formulated before this one. Norberg-Schulz had done so in Intentions in Architecture, but without as succinct a statement of activities as we proposed. It is easily arguable that our concision lacked specificity and completion. Halprin's RSVP Cycles outlines the same basic premises as our system, but put much more emphasis on Scoring, i.e., the process model, than our system. We sought a balance among the four and felt no need to turn process into the governing aesthetic principle.

4. For example one can cite the five orders, LeCorbusier's five elements of a new architecture, Maki's five operational categories for linkage, Lynch's five topological constants of urban form Lyndon's five ways to people places, even the New York five.

5. Martin Heidegger, "The Question Concerning Technology," The Question Concerning Technology and Other Essays, translated by William Lovitt, Harper \& Row, Hagerstown, 1977. Much of the discussion later in the present essay derives from Heidegger's thought, however, the ideas, although they are similar to his and have been refined in light of his thinking are my own. I have used Heidegger's neologism's to describe my thoughts because even though they sound awkward, pedantic and contrived they are remarkably precise and succinct. Any misuse of these is my fault exclusively.

6. Ibid., p. 6

7. Susan Sontag, "Against Interpretation," Against Interpretation, Dell, New York, 1978, p. 7

8. Gregory Bateson, Steps to an Ecology of Mind, Ballantine, New York, 1972, pp. 426-434. 